\title{
Opportunities and Challenges of Wisdom Pension under the background of Aging
}

\author{
Li Jiaxin ${ }^{1, *}$, Zhang Wenjing ${ }^{2}$ \\ ${ }^{I}$ Institute of Political Science and Law, University of Jinan, Jinan, Shandong, China \\ ${ }^{2}$ Research Office, Women's Development Research Center of Shandong Province, Jinan, Shandong, China \\ *Corresponding author. Email: 503615033@qq.com
}

\begin{abstract}
At present, China's population development has already entered the aging period, facing the increasingly serious population aging pressure, as a kind of revolution to the traditional pension model, wisdom pension emerges in response to the trend, providing new ideas and ways to solve the dilemma of the elderly in our country. Based on this, this paper deeply analyzes the current situation of wisdom pension, explores the existing problems, and hopes to provide thinking for the development of wisdom pension in China.
\end{abstract}

Keywords: Wisdom pension, Service for the aged, Ageing of population

\section{RAISING OF THE PROBLEM}

\subsection{Research background}

Since China officially entered the senior-oriented society in 1999, the degree of aging has been deepening at a fast speed, and the demand for old-age care services has been expanding rapidly. According to the 2018 Statistical Bulletin on the Development of Civil Affairs, by the end of 2018, there were 249 million people aged 60 or over in China, accounting for $17.9 \%$ of the total population, among which 167 million people aged 65 or over accounted for $11.9 \%$. The proportion of people aged 60 and over has grown over time. The reason is that with the advancement of China's reform and opening up, the quality of life of the Chinese people is getting better and better than in the past, the medical conditions have been greatly improved and enhanced, and the average life expectancy of the elderly population in China has been significantly extended. However, China entered the aging society under the condition of relatively underdeveloped economy, which is a situation of "getting old before getting rich", which has brought serious challenges for China to solve the pension problem.

\subsection{Objective and significance of this study}

At present, the home-based pension mode still occupies a basic position in China's pension service system, but this traditional pension mode has been difficult to meet the needs of the elderly, and the wisdom pension has emerged at the historic moment. China's intelligent elderly care service started late and developed slowly. As an industry not long after its emergence in China, it is facing many difficulties and challenges.

This paper attempts to discuss the problems existing in the development of wisdom pension in China under the overall background of aging society, hoping to promote the development of wisdom pension in the new era of China.

\section{LITERATURE REVIEW}

The concept of "Wisdom Pension" was first put forward by the UK Life Trust. It aims to provide intelligent elderly care services for the home-based elderly through the Internet of Things system platforms such as the government, communities and medical institutions. ${ }^{[1]}$ Specifically, this service refers to the use of advanced computer technology to develop a system platform for the elderly at home, families, communities, and institutions, and use this platform to provide timely and effective intelligent elderly care services for the elderly. At the same time, the use of this platform can effectively link related elderly care resources, such as governments, institutions, communities, medical staff, family children, etc. The United States is the first country to start the research and development of old-age care technology. Since the 1990s, the United States has formulated the standard reporting system implemented 
by old-age care institutions. Most foreign scholars' studies on wisdom pension are analyzed from the perspective of artificial intelligence and advanced medical technology and equipment. They pay more attention to "intelligence" and bring convenience to the elder's old-age life through intelligent forms.

In China, the research on wisdom pension started relatively late. In 2007, Hu Liming published the "new digital home endowment community solutions" in the concept of "digital endowment", the concept of "information endowment" appeared in 2010, until 2013, the academic circle will be "digital endowment", "information endowment", "technology endowment" and other concepts collectively referred to as "wisdom pension ". A group of domestic scholars from different angles to define wisdom pension, the development of wisdom pension has made a positive role in promoting. From the perspective of the needs of the elderly, Professor Zuo Meiyun believes that wisdom pension is to provide the elderly with safety protection, medical rehabilitation, leisure and entertainment services, and realize the life value of the elderly. From the perspective of home care, Liu Jianbing believes that the core of smart home care is smart home care. ${ }^{[2]}$

To sum up, domestic and foreign scholars have given their own professional perspective on the wisdom pension, and their research on the wisdom pension in the new era of the development of the wisdom pension to provide some help.

\section{THE STATUS QUO AND ADVANTAGES OF INTELLIGENT PENSION}

\subsection{Current status of domestic wisdom pension}

At present, various regions in my country are actively developing local wisdom pension services based on the successful experience at home and abroad and combining their own regional characteristics, to realize the transformation of old-age service mode, to relieve the pressure of home-based old-age service, promoted the development of the elderly care service industry and nurtured various types of wisdom pension service models. With the support of the government and people from all walks of life, some cities in China have seen the embryonic form of wisdom pension, and many excellent projects have been implemented.

\subsection{Advantages of wisdom pension}

On the one hand, the country is vigorously promoting wisdom pension. On February 6, 2017, the Ministry of Industry and Information Technology, the Ministry of Civil Affairs, and the National Health and Family Planning Commission issued the Action Plan for the Development of Smart Health and Elderly Care Industry (2017-2020) (MIIT Electronic [2017] No. 25). The development of Smart Health and Elderly Care Industry has risen to the height of national strategy. The document puts forward that the intelligent health care industry is an important measure to realize the effective docking and optimal allocation of various health care resources, promote the intelligent upgrading of health care services, and improve the quality of health care services. ${ }^{[3]}$ In 2017, the State Council proposed the implementation of the "Internet + " pension project in the "Thirteenth Five-Year" development plan for the elderly.This series of measures shows the state's support and affirmation of smart elderly care.In 2019, the "Notice of the General Office of the General Office of the Ministry of Industry and Information Technology of the Ministry of Civil Affairs and the General Office of the National Health Commission on Launching the Third Batch of Pilot Demonstrations of Smart Health and Elderly Care Application" standardizes the pilot standards, and continuously expands the scale and coverage of the pilot to provide for the elderly. The development of the service industry pointed out the direction and promoted the implementation of relevant policies to ensure the implementation of smart elderly care services.

On the other hand, the proposal of the wisdom pension service system conforms to the development trend of the aging society. With the continuous development of China, the heterogeneity of the elderly population is increasing, and the structure of pension demand is changing. Compared with the elderly in the 1930 s, 1940s and 1950s, the new elderly in the 1960s have improved their overall level in education, career structure, economy and hobbies, and their personalized and humanized needs for old-age care services have become more intense. ${ }^{[4]}$

In addition, according to the "36th Statistical Report on Internet Development in China", there are many elderly people who use the Internet, and the proportion of Chinese Internet users has increased rapidly in recent years, especially in terms of access to elderly care services. In view of the large demand, the prospects for wisdom elderly care services using Internet technology are broad.

\section{PROBLEMS EXISTING IN THE CURRENT INTELLIGENT PENSION MODEL}

\subsection{The wisdom pension model is single, and its development is still at the primary level}

At present, the design, function and operation of the wisdom pension model are still relatively simple. It is still in the exploratory stage and at the primary level, so it can hardly be called a comprehensive, composite, efficient and stable system. At present, many practices and operations of wisdom pension lack a comprehensive 
survey of the elderly group, and most of the current wisdom pension service mode in China only focuses on the development of wisdom pension science and technology, ignoring the humanistic services of wisdom pension and the needs of the elderly themselves. The existing model still has the feature of one-sided, and has not yet realized the systematic and frame-based goal based on the service needs of the elderly.

Therefore, first of all, the basic foothold of the wisdom pension mode should be clear. It should not be defined as a pure commercialization and the pursuit of interests. Its ideal state should be based on the humanistic spirit, in line with the value concept of service first and public welfare as the starting point to innovate the wisdom pension operation mode. It still needs efforts to realize the framework of wisdom pension development. We can build a framework through links and intelligent technology systems to further subdivide the business, so as to better meet the personalized service needs of the elderly group.

\subsection{The degree of social cognition of wisdom pension service is low}

Wisdom pension service is closely related to the quality of life of the public, and the public's high awareness of wisdom pension service is the basis of its development, especially the elderly group. However, another important reason for the inadequate development of the wisdom pension service in China is that many elderly people are still not familiar with the wisdom pension service, do not know the advantages of the wisdom pension service, and choose the traditional pension model. In addition, the elderly are slow to accept new things and unable to operate and use the existing pension software skillfully. Moreover, even if the elderly use wisdom pension products with the help of their relatives, most of them still believe that such products are unreliable and unsafe and may disclose personal information.

Based on this, the use of Internet records of the old people's data need to take strict privacy protection measures to avoid improper use by criminals, eliminate information security risks, unrestricted application of technical means and other negative effects; In addition, knowledge popularization and information publicity should be strengthened to promote the public to form a clear and unified understanding of the smart pension service, so that the elderly groups are willing to actively understand and accept the new pension service mode.

\subsection{There is a mismatch between supply and demand of wisdom pension services}

Although the current our country are actively involved in local wisdom pension, but in real life, intelligent equipment and product design limited, services is relatively single, the accurate grasp the characteristics of the elderly population is insufficient, more concentrated in two aspects of life care and health care, and in the elderly themselves demand side can't well satisfy the elderly. In addition, due to the knowledge level, memory, living habits and other reasons of the elderly group, even though there are an endless stream of intelligent pension products, many of them have very low user experience, and a number of intelligent pension services are beyond the affordability of ordinary people. In general, there is a serious mismatch between supply and demand in the current development of wisdom pension services. The services provided by the smart pension model cannot match properly with the needs of the elderly, and there is no balance between the two.

In the face of the mismatch between supply and demand of wisdom pension services in China, we should more effectively adjust and optimize the types of smart products from the perspective of the elderly, increase the promotion of smart devices, and improve the utilization rate and user experience of smart facilities and equipment; The products developed should be more in line with the needs of the elderly, so as to truly understand the thinking of the elderly and meet their needs, so as to achieve the balance between supply and demand for the development of wisdom pension services as far as possible.

\subsection{Not close to the community}

In our country, home care is a traditional mode of care for the aged, and it is the mode adopted by most families. The home care model is inseparable from the community where the elderly live. Therefore, if you want to solve the problem of care for the elderly, you need to start with the community. However, at present, wisdom elderly care services in my country are mostly used in more advanced elderly care institutions. Of course, the price is relatively high, and there is a certain distance from the lives of ordinary people. It has not reached the original intention of convenience and benefit for the people, and it is difficult to realize the development results of wisdom elderly care for everyone.

With the gradual and in-depth development of wisdom elderly care, increasing its popularity is an inevitable requirement for wisdom elderly care. Relying on the community is the only way for the wisdom elderly care industry to increase its popularity. Moreover, elderly care institutions mainly provide unified and specialized elderly care services, which lack advantages in meeting the personalized needs of the elderly compared with community elderly care. Therefore, the development of wisdom elderly care needs to rely on the community and be combined with community elderly care. 


\section{CONCLUSION}

China's wisdom pension is in its initial stage, but it is also a period of opportunity for rapid development, and there are many problems to be solved. In order to effectively improve the level and quality of the elderly care services in both material and spiritual aspects, and strengthen the learning and exchanges with foreign advanced intelligent elderly service institutions and talents. Strengthen wisdom pension service and make full use of modern means of science and technology, the formation of the service model, business model, technology financing mode of harmonious coexistence of pension service mode to raise the old-age service to a new level is the only way to solve the dilemma of old-age service in China. ${ }^{[5]}$

In addition, the contradiction of traditional family pension model in China is increasingly prominent, the effective service of community and pension institutions is insufficient, coupled with the change of thinking of the new generation of middle-aged people. Therefore, this article analyzes the current development status of wisdom elderly care and the existing problems of the current wisdom elderly care model in order to provide some thoughts on the current development of wisdom elderly care in my country. Wisdom pension is the mainstream trend of the future endowment, the society should pay more attention to this problem, its development needs us to pay more efforts.

\section{REFERENCES}

[1] Xie Lanxu. Wisdom pension: Let the "empty nest elderly" no longer be alone. Shanghai Information Technology, 2014(04): 50-52.

DOI: $10.3969 /$ j.issn.1672-8424.2014.04.010.

[2] Yang Mei. A review of research on smart elderly care in my country. World of Labor and Social Security, 2020(21): 26-27.

DOI: $10.3969 /$ j.issn.1007-7243.2020.21.013.

[3] Wei Yan, Xu Yun. Difficulties and Paths of the Development of Smart Health Care IndustryTaking Shaanxi Province as an Example. Journal of Xi'an University of Finance and Economics, 2020, 33(03): 37-45.

DOI: $10.3969 /$ j.issn.1672-2817.2020.03.005.

[4] Jia Yujiao, Wang Cong. The construction of a demand-oriented smart home care service system. Inner Mongolia Social Sciences, 2020, 41(05): 166$172+213$.

DOI: 10.14137/j.cnki.issn1003-5281.2020.05.023.

[5] Zhang Lei, Han Yongle. The current main models, existing problems and countermeasures of smart elderly care in my country. Social Security Research, 2017(02): 30-37.

DOI: $10.3969 /$ j.issn.1674-4802.2017.02.003. 